\title{
Use of activated red clay soil from Kiteto district, Tanzania, as a remedial method for high fluoride levels in drinking water
}

\author{
Othman Chande Othman ${ }^{1,}$, , Joseph Yoeza Naimani Philip ${ }^{1}$, Mihayo Sahani Nkinda ${ }^{2}$ \\ ${ }^{1}$ Chemistry Department, University of Dar es Salaam, P. O. Box 35061, Dar Es Salaam, Tanzania \\ ${ }^{2}$ Chemistry Department, Water Development and Management Institute, P. O. Box 35059, Dar Es Salaam, Tanzania \\ Email address: \\ o_chande@yahoo.co.uk (O.C. Othman), mihayonkinda@yahoo.com (M. S. Nkinda), josephyoeza68@yahoo.com (J. Y. N. Philip)
}

\section{To cite this article:}

Othman Chande Othman, Joseph Yoeza Naimani Philip, Mihayo Sahani Nkinda. Use of Activated Red Clay Soil from Kiteto District, Tanzania, as a Remedial Method for High Fluoride Levels in Drinking Water. International Journal of Science, Technology and Society. Vol. 2, No. 5, 2014, pp. 115-120. doi: 10.11648/j.ijsts.20140205.14

\begin{abstract}
The fluoride levels in the water samples were determined potentiometrically using a fluoride ion selective electrode. Different experiments on remediation of fluoride containing water with activated clay soil were carried out. Studies on effect of calcination temperature on activation of clay, minimum amount of calcinated clay soil giving optimum defluoridation, effect of contact time for optimal defluoridation and reusing activated soil for defluoridation of water were performed. The best activation temperature for the red clay soil from Kiteto District was found to be $700{ }^{\circ} \mathrm{C}$. For best results, the clay should be heated at this temperature for 3 hours, allowed to cool then used. The optimum water defluoridation contact time was found to be 8 hours. It was established that for $100 \mathrm{~mL}$ of fluoridated water with $4.59 \mathrm{mg}-\mathrm{F} \mathrm{L}^{-1}$, a minimum of $10 \mathrm{~g}$ of calcinated clay soil was required to reduce the concentration of fluoride ions to $\leq 1.1 \mathrm{mg}-\mathrm{F} \mathrm{L}^{-1}$ which is well below the WHO recommended level of $1.5 \mathrm{mg}-\mathrm{F} \mathrm{L}^{-1}$ for potable drinking water. The results also showed that the activated red clay soil can be repeatedly dried and re-used for the defluoridation process for a maximum of four times. It is recommended that the local red clay soil properly activated as described be used for the defluoridation of drinking water from Kiteto district, Tanzania. Investigation of possible usage of the activated clay soil for defluoridation of drinking water of other areas in the country is advocated.
\end{abstract}

Keywords: Defluoridation, Activated clay soil, Adsorption, Kiteto-Tanzania, Potable water

\section{Introduction}

Fluoride containing minerals exist naturally in the earth's crust causing soluble fluoride salts to continuously enter into groundwater. It is well known that water containing fluoride ions at low concentration of about 1 mg-F L ${ }^{-1}$ have beneficial effects on teeth by preventing and reducing tooth decay [1]. However, drinking water with high concentration of fluoride ions causes dental and skeletal fluorosis as well as osteoporosis [2]. According to [3] high fluoride water sources are widespread and present a problem for drinking water supply authorities in several areas of Tanzania. The problem is prevalent in the rift valley zones in northern and south western Tanzania, which is associated with volcanic activity and in the crystalline basement complex of the central plateau. The identified regions that have high fluoride problems in their groundwater include Shinyanga, Tabora, Dodoma, Singida, Arusha, Kilimanjaro, Musoma, Manyara, Mbeya and Rukwa [3]. In Manyara region, the prevalence of dental fluorosis is commonly found in Mbulu district [4]. However, the Kiteto District Council in Manyara region has recently observed incidences of brownish stains on teeth among native children of about 3 years old in the district indicating a possibility of high levels of fluoride ions in the drinking water in this area too. As a result of this observation, levels of fluoride ions in water sources of this area were quantified and this problem was established. Therefore, the need to investigate possible methods to reduce the concentration of fluoride ions in the ground water sources of this district to nationally approved levels [5] arose. There are basically two approaches for treating 
water sources to remove fluoride: flocculation and adsorption [6]. Flocculation method (Nalgonda technique) basically uses alum (hydrated aluminium salts) to flocculate fluoride ions in the water under alkaline conditions to produce flocs that are heavier than water which settle to the bottom of the container [7]. The adsorption approach is to filter water down through a column packed with a strong adsorbent, such as activated alumina $\left(\mathrm{Al}_{2} \mathrm{O}_{3}\right)$, bone charcoal or ion exchange resins. The adsorbent becomes saturated with fluoride ions and has to removed or backwashed with a mild acid or alkali solution to clean and regenerate it. The fluoride rich effluent from the backwashing must be disposed of carefully to avoid re-contaminating any groundwater [8]. Most of these methods need chemicals to be purchased and equipment to be built thus necessitating extra funds from the district councils and the community.

Use of locally available material would make the technology manageable and sustainable by the local community as it would make the whole process financially achievable by the district council. This study reports on defluoridation of Kiteto underground water before public usage by remediating with activated red clay soil also locally found in Kiteto district, Tanzania.

\section{Materials and Methods}

\subsection{Water and Clay Sampling}

Water samples from Kiperesa and Makame wards domestic water sources were collected using high-density polyethylene (HDPE) bottles which were previously washed with phosphate-free detergent and rinsed with de-ionized water. The samples were preserved at about 1 $4{ }^{\circ} \mathrm{C}$ in Igloo cooler containers containing ice cubes and transported to the Chemistry Laboratory, the University of Dar es Salaam where they were preserved in a refrigerator set at $4{ }^{\circ} \mathrm{C}$. These samples were analyzed for fluoride concentration within the week. The red clay soil sample of about $10.0 \mathrm{~kg}$ was obtained by boring holes at sampling sites at Kiperesa ward. The samples were collected, stored in plastic bags and transported to Chemistry Department Laboratory, University of Dar es Salaam for activation and defluoridation studies.

\subsection{Water Analysis}

Using the calibrated fluoride ion selective electrode, 10 $\mathrm{mL}$ of the sample solution and $10 \mathrm{~mL}$ of the TISAB II were transferred into a clean $50 \mathrm{~mL}$ beaker while being stirred thoroughly. The electrode was thoroughly rinsed with de-ionized water, blot dried and dipped into the sample. The fluoride concentration in the water sample was then recorded. The experiments were done in triplicate. Standard addition spikes of the fluoride standard solution were then added and the new fluoride concentrations determined. The standard addition plots were used to ascertain the concentration of fluoride ion in the collected water samples.

\subsection{Defluoridation Studies Using Calcinated Red Clay Soil}

\subsubsection{Effect of Calcination Temperature on Defluoridation Capability of the Clay}

Six portions of red clay soil each of about $15 \mathrm{~g}$ were transferred into different porcelain crucibles. Each of the crucibles containing red soil was dried and subsequently fired for three hours at different temperatures, i.e. $300{ }^{\circ} \mathrm{C}$, $400{ }^{\circ} \mathrm{C}, 500{ }^{\circ} \mathrm{C}, 600{ }^{\circ} \mathrm{C}, 700{ }^{\circ} \mathrm{C}$ and $800{ }^{\circ} \mathrm{C}$ then left to cool to room temperature. $10 \mathrm{~g}$ of each of the fired clay samples were transferred into separate plastic bottles followed by $100 \mathrm{~mL}$ of the water containing $4.59 \mathrm{mg}-\mathrm{F} \mathrm{L}^{-1}$ in each bottle. The blank sample contained only the water with no fired clay in it. The content in the plastic bottles were gently agitated on a shaker for 6 hours and thereafter left to stand for 12 hours. The water solutions were then decanted and analyzed for fluoride concentrations. The experiments were conducted in triplicate. The results were recorded and a plot of recovered fluoride concentration versus firing temperature of activated clay was drawn. The best firing temperature was then determined.

\subsubsection{Minimum Amount of Calcinated Clay Soil Giving Optimum Defluoridation}

The selected masses of activated clay soil were 2, 4, 6, 8, 10,12 and $14 \mathrm{~g}$ per $100 \mathrm{~mL}$ of fluoride containing water. Each mass of the calcinated clay soil was mixed with 100 $\mathrm{mL}$ of water containing $4.59 \mathrm{mg}-\mathrm{F} \mathrm{L}^{-1}$ in a plastic bottle. The content in the plastic bottles were gently agitated on a shaker for 6 hours and left to equilibrate overnight. The clear solutions were then decanted and analyzed for fluoride concentrations. The experiments were conducted in triplicate. The results were recorded and a plot of recovered fluoride concentration versus mass of activated clay used was drawn. The minimum amount of clay giving optimum defluoridation was then determined.

\subsubsection{Effect of Contact time}

Seven plastic bottles each containing $100 \mathrm{~mL}$ of water with $4.59 \mathrm{mg}-\mathrm{F} \mathrm{L} \mathrm{L}^{-1}$ were used. Activated clay soil fired at $700{ }^{\circ} \mathrm{C}(10 \mathrm{~g})$ was transferred into each of the plastic bottles. The content in the plastic bottles were then gently agitated using the shaker. After each of the selected contact times, i.e. $2,4,6,8,10,12$ and 24 hours, the content of one of the plastic bottles was centrifuged, and the clear solution decanted and analyzed for fluoride concentration. These experiments were conducted in triplicate. The results were recorded and a plot of recovered fluoride concentration versus time of contact was drawn and the minimum effective contact time determined.

\subsubsection{Reusability of Calcinated Clay Soil}

$100 \mathrm{~g}$ pre-used clay soil which was previously calcinated at $700{ }^{\circ} \mathrm{C}$, was heated for three hours to dry. $10 \mathrm{~g}$ of the dry soil were transferred into a clean plastic bottle followed by $100 \mathrm{~mL}$ of water with $4.59 \mathrm{mg}-\mathrm{F} \mathrm{L}^{-1}$. The contents in the plastic bottle were gently agitated for 8 hours, and then left 
undisturbed overnight. Clear decanted water was then analyzed for fluoride concentrations. The dried soil was reused for a similar experiment and this was repeated four times for experiments on fluoride removal. The results were recorded and a plot of recovered fluoride concentration versus reuse of the clay drawn. The reusability potential of the activated clay was then determined.

\section{Results and Discussion}

\subsection{Concentration of Fluoride in Water Samples from Kiteto District}

The highest of fluoride concentration was $5.91 \mathrm{mg}-\mathrm{F} \mathrm{L}^{-1}$ and the lowest concentration was $2.67 \mathrm{mg}-\mathrm{F} \mathrm{L}^{-1}$ (Table 1). High level of fluoride concentrations in groundwater occurs naturally in tectonically active areas [9]. The main source of fluoride in ground water is usually due to alkali weathering of sedimentary rocks and igneous rocks.

Minerals like fluorspar, cryolite and fluorapatite are considered fluoride bearing minerals from which fluoride finds its path to groundwater through infiltration [10].

The use of phosphate fertilizers in agriculture activities also accounts for additional fluoride ions levels in the soil [11].

Table 1. Concentration of fluoride ions $\left(m g-F L^{-1}\right)$ in water samples from Kiperesa and Makame wards, Kiteto district

\begin{tabular}{lll}
\hline \multirow{2}{*}{$\begin{array}{l}\text { Sampling } \\
\text { Site }\end{array}$} & \multicolumn{2}{c}{ Fluoride Concentration $\left(\mathbf{m g - F ~ \mathbf { L } ^ { - 1 } )}\right.$} \\
\cline { 2 - 3 } & Triplicate raw data & Average \pm Standard deviation \\
\hline Kiperesa pt1 & $5.93,5.90,5.89$ & $5.91 \pm 0.02$ \\
Kiperesa pt2 & $3.98,3.96,4.10$ & $4.01 \pm 0.08$ \\
Makame & $2.69,2.71,2.59$ & $2.67 \pm 0.07$ \\
\hline
\end{tabular}

Since fluoride concentration in the water sources from Kiteto district exceed the WHO acceptable level of 1.5 $\mathrm{mg}-\mathrm{F} / \mathrm{L}$ [12], there is a need for remedial measures to reduce these levels so that the water complies with drinking water regulations and the water sources become suitable domestic water supply sources [13].

\subsection{Defluoridation Studies Using Calcinated Red Clay Soil}

\subsubsection{Effect of Calcination Temperature on Defluoridation Capability of the Clay}

The rate of fluoride removal from the water was found to be relatively similar for non-activated clay soil up to clay soil activated at $400{ }^{\circ} \mathrm{C}$ (Table 3.2). The minimal fluoride removal efficiency from non-activated clay soil up to $400{ }^{\circ} \mathrm{C}$ was contributed by removal of physical adsorbed water molecules [14].
Table 2. Defluoridation of $100 \mathrm{~mL}$ of water containing $4.59 \mathrm{mg} \mathrm{L}^{-1}$ fluoride ion using $10 \mathrm{~g}$ of non-activated and activated clay soils of different temperatures

\begin{tabular}{lll}
\hline $\begin{array}{l}\text { Activation } \\
\text { temperature }\left({ }^{\circ} \mathbf{C}\right)\end{array}$ & \multicolumn{2}{c}{ Fluoride Concentration $\left(\mathbf{m g - F ~} \mathbf{L}^{-\mathbf{1}}\right)$} \\
\cline { 2 - 3 } & Triplicate raw data & $\begin{array}{l}\text { Average } \pm \text { Standard } \\
\text { deviation }\end{array}$ \\
\hline Raw soil $\left(29^{\circ} \mathrm{C}\right)$ & $3.41,3.71,3.51$ & $3.54 \pm 0.15$ \\
300 & $3.16,3.25,3.18$ & $3.20 \pm 0.05$ \\
400 & $3.03,3.12,3.06$ & $3.07 \pm 0.05$ \\
500 & $2.60,2.60,2.53$ & $2.58 \pm 0.04$ \\
600 & $2.10,2.21,2.15$ & $2.15 \pm 0.06$ \\
700 & $1.15,1.10,1.18$ & $1.14 \pm 0.04$ \\
800 & $1.10,1.20,1.11$ & $1.14 \pm 0.06$ \\
\hline
\end{tabular}

This result was caused by surface modification or change in the composition of the adsorbent molecules. In addition, heat treatment may remove hydroxyl groups from the surface, and may decrease the number of reactive sites [14].

The fluoride removal efficiency was relatively increased from clay soil activated at $500{ }^{\circ} \mathrm{C}$ to $600{ }^{\circ} \mathrm{C}$. The increase in fluoride removal was accelerated by the rate and capacity of fluoride binding in the clayware which varies with the firing temperature [15]. When the temperature of activation was changed to $700{ }^{\circ} \mathrm{C}$ the fluoride ion removal capacity was higher compared to clays activated at the previous lower temperatures. The level of defluoridation of $100 \mathrm{~mL}$ of water with $10 \mathrm{~g}$ of activated soil increases to a maximum at $700{ }^{\circ} \mathrm{C}$ and remains constant at $800^{\circ} \mathrm{C}$ (Figure 1).

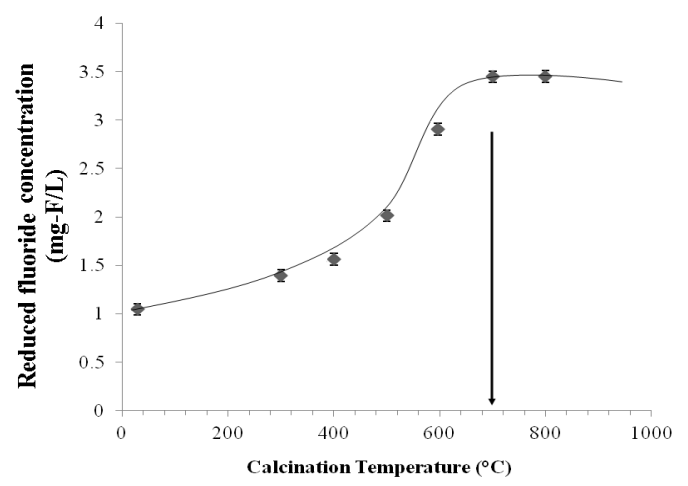

Figure 1. Effect of calcination temperature on defluoridation of water using clay soil samples

It can be concluded that the activation temperature of $700{ }^{\circ} \mathrm{C}$ has the highest removal efficiency and removal capacity. Further increases in calcination temperature reduce the removal efficiency and removal capacity of calcinated red clay soil.

\subsection{Minimum Amount of Calcinated Soil Giving Optimum Defluoridation}

The rate of adsorption of fluoride ions in the water onto 2 $\mathrm{g}$ up to $10 \mathrm{~g}$ of activated clay soil increased steadily (Table 3 ). This can be explained by the fact that an increase in mass of the adsorbent goes hand in hand with a corresponding increase in surface active fluoride adsorption sites [16]. Defluoridation capacity of the activated clay soil at $10 \mathrm{~g}$ was the highest (Figure 2). 
Table 3. Defluoridation of $100 \mathrm{~mL}$ of water containing $4.59 \mathrm{mg} \mathrm{L}^{-1}$ fluoride ion by varying amount of clay soil activated at $700{ }^{\circ} \mathrm{C}$

\begin{tabular}{lll}
\hline \multirow{2}{*}{$\begin{array}{l}\text { Mass of calcinated } \\
\text { clay soil (g) }\end{array}$} & \multicolumn{2}{l}{ Fluoride Concentration $\left(\mathbf{m g}-\mathbf{F ~ L ~}^{-\mathbf{1}}\right)$} \\
\cline { 2 - 3 } & Triplicate raw data & $\begin{array}{l}\text { Average } \pm \text { Standard } \\
\text { deviation }\end{array}$ \\
\hline 2 & $4.10,4.31,4.29$ & $4.23 \pm 0.12$ \\
4 & $3.96,4.01,3.88$ & $3.95 \pm 0.07$ \\
6 & $3.07,3.00,3.28$ & $3.12 \pm 0.15$ \\
8 & $2.49,2.39,2.55$ & $2.48 \pm 0.08$ \\
10 & $1.05,1.22,1.25$ & $1.17 \pm 0.11$ \\
12 & $1.12,1.27,1.05$ & $1.15 \pm 0.11$ \\
14 & $1.12,1.29,1.11$ & $1.17 \pm 0.10$ \\
\hline
\end{tabular}

Increase in available surface active sites being facilitated by an increase in the adsorbent dose has also been advocated by [17].These results suggest that the proper ratio of water samples and the amount of activated clay soil in weight during mixing should always be considered, the optimum being $10 \mathrm{~g}$ of activated soil for every $100 \mathrm{~mL}$ of fluoride containing water. Fluoride removal using activated clay soil from $10 \mathrm{~g}$ to $14 \mathrm{~g}$ was found to be similarly high, that is, using $10 \mathrm{~g}$ of activated soil and above the fluoride removal capacity remains constant (Figure 2 and Table 3 ). The main cause of this phenomenon is due to higher number of adsorbent dose with enough vacant sites available for fluoride adsorption. Nonetheless as the time went on, the vacant sites become exhausted [18] and no further fluoride adsorption was noticed from using more than $10 \mathrm{~g}$ of the activated clay soil.

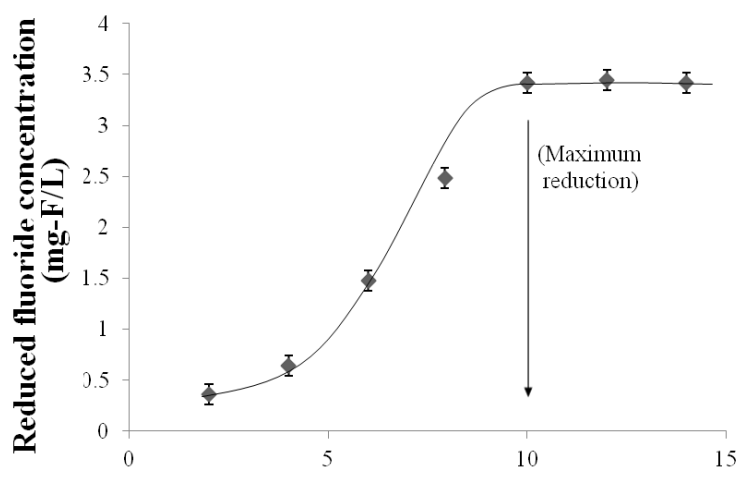

Mass of calcinated clay soil (g)

Figure 2. Amount of activated $\left(700^{\circ} \mathrm{C}\right)$ red clay soil for effective defluoridation of water

\subsection{Effect of Contact time on Defluoridation}

Results (Figure 3) show that the removal of fluoride ions from water increases steadily with increase in contact time between calcinated clay soil and fluoridated water. This increase is from 2 hours to 6 hours and reaches a maximum at $8 \mathrm{hrs}$ of contact time. From 8 to 12 hours of contact time the defluoridation of water was observed to be high but constant (Figure 3).
Table 4. Effect of contact time in the defluoridation of $100 \mathrm{~mL}$ of water containing $4.59 \mathrm{mg}-\mathrm{F} \mathrm{L} \mathrm{L}^{-1}$ fluoride ion using $10 \mathrm{~g}$ of clay soils activated at $700{ }^{\circ} \mathrm{C}$

\begin{tabular}{lll}
\hline \multirow{2}{*}{$\begin{array}{l}\text { Contact } \\
\text { time }(\mathbf{h r s})\end{array}$} & \multicolumn{2}{l}{ Fluoride Concentration $\left(\mathbf{m g - F} \mathbf{L}^{-\mathbf{1}}\right)$} \\
\cline { 2 - 3 } & Triplicate raw data & Average \pm Standard deviation \\
\hline 2 & $3.10,3.31,3.22$ & $3.21 \pm 0.11$ \\
4 & $2.46,2.60,2.38$ & $2.48 \pm 0.21$ \\
6 & $1.57,1.61,1.44$ & $1.54 \pm 0.09$ \\
8 & $1.11,1.17,1.20$ & $1.16 \pm 0.05$ \\
10 & $1.15,1.22,1.05$ & $1.14 \pm 0.10$ \\
12 & $1.12,1.15,1.19$ & $1.15 \pm 0.04$ \\
24 & $1.12,1.20,1.31$ & $1.21 \pm 0.10$ \\
\hline
\end{tabular}

This can be due to there being enough uptake of fluoride ions from the water samples caused by the longer contact time used. Lack of vacant sites for further adsorption caused by the constant deposition of fluoride ions on adsorbent materials could be the reason for this. In fact the blocked pores of the clay soil result in poor diffusion of fluoride ions into the inner surface of the adsorbent particles [19].

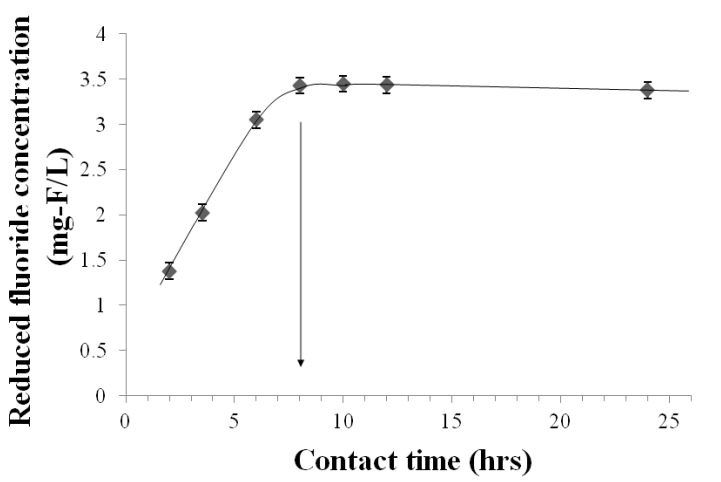

Figure 3. Effect of contact time in hours on defluoridation of water

At contact times above $12 \mathrm{hrs}$ and up to 24 hours, the fluoride removal in water samples starts to decline very slightly suggesting an equilibrium condition. At these times, the equilibrium and saturation peak had been reached and a constantly low uptake of fluoride ions from the water samples was observed [20].

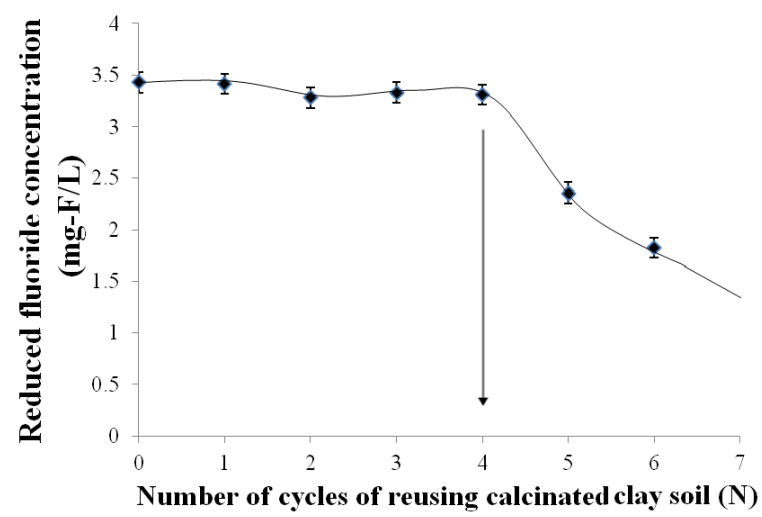

Figure 4. Reusability of calcinated clay soil from Kiteto district for defluoridation of water using $10 \mathrm{~g}$ activated clay soil in $100 \mathrm{~mL}$ of water containing fluoride. 


\subsection{Reusability of the Calcinated Clay Soil for Defluoridation}

The study on efficiency of reusability of activated clay soil for fluoride ion removal in water samples showed that the removal of fluoride ions diminishes as the activated clay soil is reused several times (Figure 4). The results show that at initial use ( 0 cycle) and the first four re-cycles ( 1 up to $4^{\text {th }}$ recycling process) the defluoridation of the water was effective using the same activated clay soils. But at the $5^{\text {th }}$ and $6^{\text {th }}$ recycling defluoridation experiments and beyond the capability for defluoridation of water was rendered poorer and finally became ineffective.

From figure 4, it can be concluded that the defluoridation of water by reusing the same amount of activated clay soil should only be done to a maximum of four times therefore allowing $400 \mathrm{~mL}$ of water with acceptable levels of fluoride in the water for every $10 \mathrm{~g}$ of activated red clay soil.

\section{Conclusions}

The use of $10 \mathrm{~g}$ of red clay soil activated at $700{ }^{\circ} \mathrm{C}$ for 3 hours in $100 \mathrm{~mL}$ of fluoridated water while thoroughly stirring for 8 hours reduces the fluoride concentration in water from $4.59 \mathrm{mg}-\mathrm{F} \mathrm{L} \mathrm{L}^{-1}$ to $1.14 \mathrm{mg}-\mathrm{F} \mathrm{L}^{-1}$, a concentration which is below the acceptable WHO and TBS standards for drinking water. Results of experiments on clay activation temperatures above $800{ }^{\circ} \mathrm{C}$ showed that there was no further improvement in the fluoride adsorption capacity of the clay. It was also observed that when the mass of activated clay soil was varied while the volume of water samples were kept constant, the fluoride removal in water increases relative to the increase in the mass of activated clay soil being used. The optimum mass of clay soil per $100 \mathrm{~mL}$ of fluoridated water was $10 \mathrm{~g}$. Increase of the contact time for activated clay soil in fluoridated water of up to 8 hours showed an increase in fluoride removal capacity of the soil reaching equilibrium where there was no further increase after 8 hours. Longer contact times $(10-24 \mathrm{hrs})$ of soil with the fluoride containing water samples had no further influence on fluoride removal capability. It can be concluded that activated $\left(700^{\circ} \mathrm{C}\right)$ clay soil from Kiteto district is the proper material for application as defluoridation medium at household level and also at community level in defluoridation of water in the district. It is recommended that investigation on possible use of activated clay soil from Kiteto district as defluoridation media for water from other fluorinated areas in the country should be conducted.

\section{References}

[1] Brindha K. and Elango L. (2011). Fluoride in groundwater: causes, implications and mitigation measures. In: Monroy, S.D. (Ed.), Fluoride properties, applications and environmental management. Nova Publishers, pp111-136.

[2] Miller-Ihli N.J., Pehrsson P.R., Cutrifelli R.L. and Holden
J.M. (2003). Fluoride content of municipal water in the United States: What percentage is fluoridated? J. Food Comp. Anal. 16: 621-628.

[3] Ayoob S. and Gupta A.K. (2006). Fluoride in drinking water. A review on the status and stress effects in India. Critical Review's in Environmental Science and Technology 36: 433-487.

[4] Kashangili J.J. (2010). Assessment of groundwater availability and its current and potential use and impacts in Tanzania. Final Report Prepared for the International Water Management Institute (IWMI) pp 1-58.

[5] TBS, (2008). TZS 789: Drinking (potable) water Specification, ICS: 13.060.20, Tanzania Bureau of Standards.

[6] Tewari A. and Dubey A. (2009). Defluoridation of drinking water: efficacy and need. Journal of Chemical and Pharmaceutical Research 1(1): 31-37.

[7] Nawlakhe W.G., Kulkarni D.N., Pathak B.N., Bulusu K.R. (1975). Defluoridation of water by Nalgonda technique. Indian Journal of Environmental Health 17(1): 26-65.

[8] Patil S.S. and Ingole N.W. (2012). Studies on defluoridation A critical review. Journal of Engineering Research and Studies 3(1): 111-119.

[9] Mckenzie J.M., Mark B.G., Thompson L.G., Schotterer U.L. and Lin P.N. (2009). A hydrogeochemical survey of Kilimanjaro (Tanzania): Implications for water sources and ages, Hydrogeology Journal 18: 985-995.

[10] Shailaja K. and Johnson M.E. (2007). Fluorides in groundwater and its impact on health. J Environ. Biol. 28(2): 331-332.

[11] Tailor G.S. and Chandel C.P.S. (2010). To assess the quality of ground water in Malpura Tehsil (Tonk, Rajasthan, India) with emphasis to fluoride concentration. Nature and Science 8: $20-26$.

[12] WHO (2011). Guidelines for drinking-water quality. 4th edition. World Health Organization, Geneva.

[13] Msonda K.W.M., Masamba W.R.L. and Fabiano E. (2007). A Study of fluoride in groundwater occurrence in Nathenje, Lilongwe, Malawi. Physics and Chemistry of the Earth, Parts, $A / B / C, 32: 1178-1184$.

[14] Shimelis B., Zewge F. and Chandravanshi B.S. (2006). Removal of excess fluoride from water by aluminum hydroxide. Bull. Chem. Soc. Ethiop. 20: 17-34.

[15] Mohapatra M., Anand S., Mishra B.K., Giles D.E. and Singh P. (2009). Review of fluoride removal from drinking water. $J$ Environ. Manage. 91: 67-77.

[16] Gomoro K., Zewge F., Hundhammer B. and Megersa N. (2012). Fluoride removal by adsorption on thermally treated lateritic soils. Bull. Chem. Soc. Ethiop. 26: 361-372.

[17] Emmanuel K.A., Ramaraju K.A., Rambabu G. and Rao A.V. (2008). Removal of fluoride from drinking water with activated carbons prepared from nitric acid activation. A comparative study. RJC Rasayan J. Chem. 1: 802-818.

[18] Shrivastava A.K. and Sharm M.K. (2012). An innovative technique for removal of fluoride from drinking water. Sci. Revs. Chem. Commun. 2: 133-140. 

Method for High Fluoride Levels in Drinking Water

[19] Deshmukh W.S., Attar S.J. and Waghmare M.D. (2009). Investigation on sorption of fluoride in water using rice husk as an adsorbent. Nature, Environment and Pollution Technology 8: 217-223.
[20] Alagumuthu G., Veeraputhiran V. and Venkataraman R. (2011). Fluoride sorption using Cynodon dactylon based activated carbon. Hemijska industrija 65: 23-35. 